\title{
OS DISCURSOS INCLUSIVOS E SEUS EFEITOS SOBRE O DISCENTE NORMAL: ESTRATÉGIAS DE GOVERNAMENTO
}

\author{
Camila Bottero Corrêa ${ }^{\mathrm{i}}$ \\ Kamila Lockmann ${ }^{\mathrm{ii}}$
}

\begin{abstract}
Resumo: O artigo objetivou analisar os discursos da inclusão escolar, materializados em documentos oficiais, e a forma como operam estratégias de governamento sobre os sujeitos ditos normais. A partir dos estudos foucaultianos, especialmente dos conceitos-ferramentas de discurso e governamento, evidenciouse um triplo movimento composto pela tríade reflexão - simulação - colaboração. No primeiro eixo observa-se que o discente dito normal é alvo de técnicas de reflexão que visam familiarizá-lo com a deficiência. Num segundo momento, ele passa a ser alvo de técnicas de simulação pautadas na lógica da diversidade. Já no terceiro eixo, observa-se a cultura da colaboração como outra forma de sensibilização à diversidade, visando uma convivência produtiva entre o sujeito normal e anormal.
\end{abstract}

Palavras Chaves: inclusão; normalização; sensibilização; governamento.

\section{LOS DISCURSOS INCLUSIVOS Y SUS EFECTOS EN EL DISCENTE NORMAL: ESTRATEGIAS DE GOBERNAMIENTO}

Resumen: El artículo tenía como objetivo analizar los discursos de inclusión escolar, materializados en documentos oficiales, y la forma en que las estrategias de gobernamiento operan sobre los sujetos normales. A partir de los estudios foucaultianos, especialmente los conceptos herramienta del discurso y la gobernamiento, se evidenció un triple movimiento, compuesto por la tríada de reflexión - simulación colaboración. En el primer eje, se observa que el llamado estudiante normal es el objetivo de las técnicas de reflexión que tienen como objetivo familiarizarlo con la discapacidad. En un segundo momento, se convierte en el objetivo de las técnicas de simulación basadas en la lógica de la diversidad. En el tercer eje, la cultura de colaboración se observa como otra forma de sensibilización a la diversidad, con el objetivo de una coexistencia productiva entre los sujetos normales y anormales.

Palabras clave: inclusión; normalización; sensibilización; gobernamiento.

\section{Introdução}

Este artigo buscou investigar como os discursos da inclusão escolar, materializados em documentos oficiais, colocam em funcionamento estratégias de governamento que operam sobre os sujeitos ditos

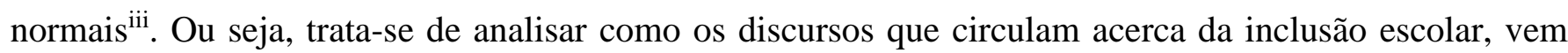
incidindo não apenas sobre os sujeitos anormais, mas também sobre as condutas dos normais, sensibilizando-os diante da presença do outro e naturalizando a diferença. Nesta pesquisa compreende-se que os discursos da inclusão se proliferam na contemporaneidade possuindo, cada vez mais, um caráter benevolente e salvacionista. Esses parecem marcar um momento em que é necessário se mobilizar por algo, que se apresenta como ideal, como uma verdade a ser efetivada em uma determinada época. 
Ao direcionar o olhar para esses discursos, percebemos a importância de colocá-los sob suspeita, uma vez que compreendemos que não há neutralidade nos mesmos. Apoiadas em Foucault, compreendemos que os discursos que circulam em nossa sociedade pertencem a uma lógica discursiva mais ampla que os regula, definindo aquilo que será considerado verdadeiro, legítimo e aceito em nosso tempo. A partir dela, "os discursos definem regimes de verdade que balizam e separam o verdadeiro de seu contrário. Desse modo, os discursos não descobrem verdades, senão as inventam". (VEIGA-NETO, 2005a, p. 122). Portanto, é esta lógica que determina um conjunto de regras que irão dar condições para o funcionamento do discurso e que vão controlar aquilo que pode ser dito em uma determinada época, pois:

[...]em toda sociedade a produção do discurso é ao mesmo tempo controlada, selecionada, organizada e redistribuída por certo número de procedimentos que tem por função conjurar seus poderes e perigos, dominar seu acontecimento aleatório, esquivar sua pesada e temível materialidade. (FOUCAULT, 2013, p. 8-9).

A partir de tais discussões percebemos o quanto se torna produtivo pensar sobre o perigo do discurso; "o que há, enfim, de tão perigoso no fato de as pessoas falarem e de seus discursos proliferarem indefinidamente?" (FOUCAULT, 2013, p. 8). Compreendemos que o perigo está posto no discurso, quando os mesmos são banalizados, no fato de nos colocarmos em um lugar comum e aceitarmos as verdades que eles nos transmitem sem pensar, problematizar e/ou questionar. Os discursos, neste momento, tornam-se cada vez mais familiares, sendo percebidos como algo natural e assumindo, aos poucos, um caráter de verdade absoluta e, por isso, inquestionável.

Isso ocorre com os discursos que circulam contemporaneamente sobre a inclusão escolar. Mais do que expor certos significados compreendemos que tais discursos fabricam modos de ser e de pensar que correspondem a uma série de regras pertencentes à determinada ordem discursiva. Os discursos inclusivos não deixam de ser desta forma "praticas organizadoras da realidade" (SOMMER, 2007, p. 58), onde "o que se faz é condicionado pelo que se diz" (SOMMER, 2007, p. 66). Assim, desnaturalizar as verdades expressas pelos discursos implica reconhecê-las como construções sociais e históricas, pertencentes à racionalidade de uma determinada época e que, por isso, tornam-se mais corretas e desejáveis. Além disso, é também reconhecer que tais verdades, proferidas em práticas discursivas, geram efeitos em cada sujeito da população.

Por meio de palavras como igualdade, diversidade, tolerância e aceitação esses discursos são apresentados à sociedade com o objetivo de sensibilizá-la e convocá-la na busca por tornar efetiva a inclusão. Desta forma, entende-se que a inclusão tem funcionado como uma estratégia de governamento, ou seja, como ação ou ato de governar (VEIGA-NETO, 2005b) que permite os sujeitos agirem sobre os outros e sobre si mesmos, tornando-se agentes de execução da inclusão e sensíveis a presença do outro. 
Veiga-Neto (2005b) propõe ressuscitar na língua portuguesa a palavra governamento, a fim de estabelecer uma distinção entre os dois sentidos dados, a partir de uma perspectiva foucaultiana, ao que se pode chamar de governo. O autor vem apontando a utilização, por Foucault, em seus escritos de Filosofia Política, de duas palavras diferentes para expor tais entendimentos. Desse modo, é proposto pelo mesmo, usar a palavra Governo com G maiúsculo, para se referir "a instituição do Estado que centraliza ou toma, para si, a caução da ação de governar" (VEIGA-NETO, 2005b, p. 16) e ainda que o vocábulo governo "passe a ser substituído por governamento nos casos em que estiver sendo tratada a questão da ação ou ato de governar". (VEIGA-NETO, 2005b, p. 16). Assim, governamento aqui passa a ser compreendido como a maneira de governar ou de conduzir as condutas dos sujeitos a partir de determinados princípios considerados verdadeiros em uma época dada.

A partir destes entendimentos, nesta pesquisa, foram analisados os discursos presentes em alguns documentos oficiais produzidos pelo Ministério da Educação, sendo: O acesso de alunos com deficiência às escolas e classes comuns da rede regular (2004); Projeto escola viva: garantindo o acesso e permanência de todos os alunos na escola (2005); Educar na diversidade: material de formação docente (2006). Tais documentos foram escolhidos para compor o material de análise por serem publicações oficiais relacionadas à temática da inclusão escolar e pelas orientações que apontam para a construção de um sistema educacional inclusivo, indicando uma conduta adequada a ser adotada frente aos sujeitos incluídos. Além disso, esses documentos também foram escolhidos devido ao público alvo para o qual estão direcionados: professores, familiares, alunos e sociedade, ou seja, por mostrarem uma ampla circulação dos discursos inclusivos na contemporaneidade.

Como aporte teórico utilizou-se os estudos pós-estruturalistas, sobretudo as ferramentas foucaultinas de discurso e governamento. Neste artigo, apresentaremos uma das unidades analíticas da pesquisa, a qual evidencia um triplo movimento composto pela tríade reflexão - simulação - colaboração. No primeiro eixo observa-se que o discente dito normal é alvo de técnicas de reflexão que visam familiarizálo com a deficiência. Num segundo momento, ele passa a ser alvo de técnicas de simulação pautadas na lógica da diversidade. Já no terceiro eixo, observa-se a cultura da colaboração como outra forma de sensibilização à diversidade, visando uma convivência produtiva entre o sujeito normal e anormal. No decorrer desse exercício analítico percebeu-se como tais discursos contribuem para naturalização da presença do outro e para o alargamento da noção de normalidade.

\section{Reflexão - Simulação - Colaboração: a tríade que age sobre o discente dito normal}

Ao analisar os documentos oficiais foi possível perceber práticas discursivas, que são direcionadas aos professores e que impõe claramente como os mesmos devem agir, para sensibilizarem os alunos 
normais à inclusão. Nos discursos analisados observa-se que estas práticas discursivas tendem a mobilizar os docentes por intermédio de orientações, para o desenvolvimento de ações que garantam a continuidade da circulação dos anormais, pelos mesmos espaços que os normais. Nestas práticas discursivas observa-se que, em alguns momentos, o professor é o alvo de estratégias que visam conduzir a sua conduta através da autocondução e, em outros momentos, ele é instrumento para agir sobre o comportamento dos discentes normais. Ou seja, nestes documentos, as ações inclusivas não se dão diretamente sobre os discentes normais, mas por meio de um processo de governamento em cadeia. Este, conforme aponta Klein (2017, p. 77), se constitui enquanto

[...] um processo de governamento (condução das condutas) que se instala a partir de um fim específico [...] e atua de forma descendente, a partir do poder em uma instância a nível macro [...] desdobrando-se, acoplando-se e incorporando as demais instâncias, até chegar ao nível micro [...], onde está a finalidade do seu exercício. É o nível micro que responderá [ou não] à finalidade da cadeia, que se instala agora no sentido ascendente, funcionando de forma idêntica, até retornar ao nível macro, onde se instituiu. O governamento em cadeia não pode ser entendido de forma linear, e sim, de forma rizomática, pois, a cada instância formam-se novas cadeias, algumas microcadeias para garantir que o poder chegue até as extremidades.

Desse modo, os discursos em questão produzem essa espécie de efeito dominó sobre os sujeitos escolares, não se tornando necessário agir diretamente sobre os discentes normais para sensibilizá-los à inclusão, ainda que o objetivo seja alcançá-los. Tais discursos mostram que as ações de condução do trabalho docente são estratégias econômicas, pois qualificam esse profissional a conduzir a conduta do discente dito normal, permitindo que ele seja subjetivado a aceitar a inclusão através de investimentos mínimos de poder.

Assim sendo, ao explorar os discursos que conduzem a prática docente evidenciamos a existência de uma tríade que age sobre o sujeito discente dito normal, composta por estratégias de reflexão, simulação e colaboração. Estas serão apresentadas por meio de três momentos. Passamos assim, a explorar o primeiro deles, onde analisamos as estratégias de reflexão que o professor é orientado a desenvolver com os alunos normais.

\section{Refletir para incluir: a busca pelo outro em mim}

As atividades de reflexão, que serão evidenciadas neste eixo analítico, são exemplos de estratégias que fazem parte do que podemos nomear como um movimento de aceitação, tolerância e respeito à diversidade. Nesse sentindo, observa-se que para que os normais possam aceitar a presença do outro, é necessário que as diferenças existentes não lhes causem estranhamento. Em outras palavras, é preciso que a presença do outro seja naturalizada. Desta forma, entendemos que ao orientar os professores a fazerem 
uma reflexão junto aos alunos normais, estas atividades buscam contribuir para o desenvolvimento do processo de naturalização das diferenças. Vejamos algumas delas a seguir:

[...]reflexão intelectual sobre o assunto, tais como: . discussão em grupo sobre filmes, pecas, desenhos, etc., que tenham como personagens, principais ou secundários, pessoas com deficiência; - redação sobre um personagem existente ou criado pelos participantes; - familiarização com alguns equipamentos usados por pessoas com deficiência por meio da introdução de alguns deles dentre outros objetos usados comumente por todos (como escova de dente, sapatos, talheres, etc.). Pode-se solicitar aos participantes que procurem identificar a função social de cada objeto; - coleta de notícia sobre o tema em jornais e revistas. Obs.: É muito importante que os participantes sejam incentivados a dizer como se sentiram durante as atividades [...] (PROJETO ESCOLA VIVA, 2005, p. 9-11).

\section{Conhecendo e tornando familiares os equipamentos} AS COISAS QUE NOS AJUDAM

Coloque numa caixa de papelão diversos objetos que usamos em nossas atividades e tarefas do dia-a-dia, como por exemplo, um par de escova de dentes, um par de óculos, uma chuteira, equipamentos de mergulho, uma régua, um capacete, talheres, etc. Inclua também alguns equipamentos usados por pessoas com deficiência: um aparelho auditivo, um livro em Braille, uma bengala longa, uma muleta, um aparelho ortopédico, etc. Reúna um pequeno grupo de alunos e peça a cada um deles que selecione e retire um objeto da caixa. [...] Essa ideia é adequada principalmente para crianças pequenas, e tem por objetivo ajudá-las a perceber as limitações sob uma ótica mais positiva, por meio da familiarização com equipamentos de apoio usados por pessoas com deficiência.[...]Quando os objetos usados pelas pessoas com deficiência são intercalados com os objetos usados pelas pessoas sem deficiência, as crianças aprendem que, da mesma forma que elas usam a escova de dentes para fazer a tarefa de realizar a higiene bucal, as pessoas com deficiência visual usam o alfabeto Braille para ler e a bengala longa para se locomover; as pessoas surdas usam o aparelho para ouvir; as pessoas com deficiência física usam muletas para se locomover, etc.[...] O contato inicial das crianças com os equipamentos é interessante, pois ele permite que elas façam perguntas, que os toquem e que descubram o que são e para que servem, sem constranger ou prejudicar o usuário. Quando, posteriormente, pessoas com deficiência visitarem a escola, as crianças já estarão familiarizadas com os equipamentos e prestarão mais atenção à pessoa do que aos objetos que ela usa. (PROJETO ESCOLA VIVA, 2005, p. 11-13, grifo nosso).

Conforme é possível visualizar, as atividades de reflexão destacadas acima propõem a aproximação e a familiarização dos alunos normais com casos e objetos utilizados por pessoas que possuam alguma deficiência. Por meio delas, pretende-se que os alunos normais estabeleçam uma relação de correspondência entre os objetos utilizados por pessoas com deficiência e os objetos úteis e necessários para a realização de ações corriqueiras, que fazem parte do seu dia-a-dia. Eles são, assim, estimulados a perceberem as familiaridades existentes entre o cotidiano do sujeito deficiente e as suas atividades diárias, 
bem como a exercerem atividades de autorreflexão, de modo a criar um conhecimento sobre si e sobre o outro. Nesse sentido essa atividade contribui para que os alunos normais visualizem as diferenças com naturalidade e é a partir dessa naturalização, à medida que os normais internalizam para si que "um aparelho auditivo é tão normal quanto uma escova de dentes", que a noção de normalidade se amplia.

Nessas atividades, observa-se que a "[...] inclusão passa a abarcar as relações interpessoais, além do estar junto (entendido como condição mínima necessária mas não suficiente para as ações de inclusão).” (LOPES; FABRIS, 2013, p. 70). As ações inclusivas desenvolvidas sobre os normais têm por objetivo tornar natural a presença do outro, isto é, buscam normalizar o dito anormal a partir da naturalização da

[...] sua presença na população entre aqueles que compõem o gradiente social em que participa, o indivíduo, além de ser "tratado" a partir do referencial de normalidade oriundo da norma (normação), é quantificado e mostrado como mais um que está enquadrado em uma zona de normalidade determinada pela noção de inclusão. (LOPES; FABRIS, 2013, p. 46).

A naturalização das diferenças faz com que a noção de normalidade se alargue, de modo a abarcar uma variedade de tipos e formas o que dá ensejo ao aparecimento das normalidades diferenciais. Estas podem ser entendidas como aquelas diferenças que ocupam o lugar da anormalidade, mas que são aceitas e vistas como naturais pelos sujeitos normais, a partir de ações pautadas pelo viés da diversidade. Tais ações contribuem para a circulação dos anormais por diversos espaços sociais, onde ocupam níveis de participação ou gradientes de inclusão.

Para compreender tal processo é necessário discutir a sua relação com o funcionamento da norma na sociedade de seguridade. Esta vai agir "na pluralização dos modelos que devem ser referência para que todos possam se posicionar dentro de limites locais, e uns em relação aos outros.”. (LOPES; FABRIS, 2013, p. 42). Ou seja, na sociedade de seguridade, não podemos considerar a existência de uma norma a priori, mas normalidades, uma vez que, é a partir do apontamento do normal em um determinado contexto e grupo que se tem uma determinação, construção e proliferação das normas. Para Foucault (2008b, p. 83), a norma na sociedade de seguridade é estabelecida "no interior das normalidades diferenciais. O normal é que é primeiro, e a norma se deduz dele, ou é a partir desse estudo das normalidades que a norma se fixa e desempenha seu papel operatório”. Todos serão, assim, capturados e incluídos de acordo com determinados critérios, construídos no interior de grupos sociais. Entende-se, portanto, que a norma vai ser produzida de acordo com as variações dos grupos. Cada um deles pode e cria novas normalidades para atender a determinadas exigências e regras sociais, permitindo que os sujeitos sejam capazes de circularem, fazerem parte e atuarem em diferentes espaços sociais.

Nesse caso, observa-se que a ação da norma de seguridade não possibilita apenas uma proliferação das normas, mas também, pode-se dizer que, muito mais, uma expansão da própria norma, uma vez que 
nos processos de normalização "o movimento não parte da norma, mas, ao contrário, faz dela um "gradiente", ou melhor, uma possibilidade de expandir a norma e torná-la flexível para outros enquadramentos que fogem da dicotomia "normal/anormal"." (RECH, 2010, p. 75). Portanto, cada sujeito, independente de toda e qualquer diferença, passa a ser incluído em uma posição ou situação diferenciada, de modo a ocupar um lugar na zona de normalidade. Normais e anormais passam, dessa maneira, a ser incluídos em "diferentes níveis de participação ou gradientes de inclusão". (LOPES et. al, 2010, p. 5).

Em uma sociedade de seguridade, as práticas que são postas em operação recaindo sobre os processos de normalização dos sujeitos anormais, permanecem existindo. No entanto, a novidade é que a ênfase dessas práticas não recai apenas sobre eles. Para que os anormais ocupem e se mantenham nessa zona de normalidade, é preciso "normalizar os fluxos que podem atrapalhar o desenvolvimento e a articulação interna e externa a eles." (LOPES et al, 2010, p.12). Com isso, talvez possamos dizer que a ênfase das práticas em uma sociedade de seguridade recai sobre os processos e estratégias de subjetivação, agindo sobre os sujeitos normais para promover e efetivar a aceitação da presença do outro. Conforme aponta Rech (2010, p. 75),

[...] o objetivo é fazer com que o indivíduo seja normalizado através da naturalização da sua presença e se enquadre em uma das distribuições permitidas pela curva de normalidade. Falando de outro modo, é necessário que o "anormal" ocupe um lugar nessa curva, a fim de permitir o seu reconhecimento frente a sociedade. Para que esse reconhecimento aconteça de maneira "natural", a população precisa ser educada para reconhecer esse dito "anormal" e conviver com ele sem estranhamento. O objetivo é torná-la apta para aceitar a sua presença.

A produção dessas normalidades diferenciais não vai ocorrer só pela normalização dos anormais, ou melhor, do seu enquadramento em uma zona de normalidade. Para que o sujeito dito anormal esteja incluído em diferentes níveis de participação e/ou gradientes de inclusão, é necessário que seja reconhecido pela sociedade, que sua presença seja aceita. Dessa forma, outras intervenções sobre os sujeitos tornam-se necessárias, principalmente aquelas que são direcionadas aos normais, como vimos nas estratégias acima apresentadas.

Diante disso, observa-se que embora os discursos destacados contribuam para a naturalização das diferenças e, por isso, com o alargamento da noção de normalidade, a fronteira entre normal e anormal permanece existindo, no entanto, com uma demarcação mais sutil. Um segundo conjunto de estratégias, que gostaríamos de destacar neste momento, reforça essa ideia. Trata-se das técnicas de simulação sugeridas aos professores para realizarem junto aos alunos normais.

\section{Vivenciar para incluir: a (im)possibilidade de simular a deficiência}


Nos documentos oficiais é possível observar exemplos de práticas de condução do trabalho docente que visam colocar em operação procedimentos para sensibilizar o aluno dito normal às deficiências. Tais práticas estão em evidência nas atividades que orientam os docentes a convidarem os discentes normais à vivenciarem a deficiência por meio de simulações. Vejamos a seguir uma dessas propostas:

\section{COMO É SER UM DEFICIENTE VISUAL?}

Objetivo - Ajudar as crianças a perceberem como é precisar de ajuda e como oferecer e dar ajuda a uma pessoa com deficiência visual.

Material - Vendas pretas para todo o grupo.

Simulando as deficiências

Procedimento - Divida o grupo em pares, sendo que enquanto uma criança representará a pessoa cega, a outra será o acompanhante. Após um certo tempo, a dupla deverá inverter os papéis, de forma que aquele que representou a criança cega, será agora o acompanhante, enquanto que aquele que foi o acompanhante, será agora a criança cega. Explique claramente que todos os alunos terão a oportunidade de vivenciarem os dois papéis: o de criança cega e o de acompanhante. [...] Explique que o papel do acompanhante é estar ao lado do cego para oferecer ajuda e dar essa ajuda quando for solicitada, ou aceita. Explique que é importante perguntar se ele precisa de ajuda e de que forma essa ajuda pode ser dada. Os pares serão orientados a realizar diversas atividades, tais como: ler um material escrito na biblioteca da escola, tomar água no bebedouro, pedir uma informação na secretaria, dar um passeio no pátio da escola, utilizar o banheiro, etc.

Discussão - Em pequenos grupos formados pelos pares originais, discuta as seguintes questões:

1._Como você se sentiu simulando uma pessoa com deficiência? 2._Você acha que ficou mais atenta para perceber os sons e sentir os objetos?

3._Como você se sentiu simulando o acompanhante?

4._Como acompanhante quais as coisas que você fez para ajudar seu colega cego?

5._Seu colega cego concorda com você?

6._Você sentiu mudança na sua atitude quando estava vivenciando ser cego e quando estava sendo acompanhante?

7._Qual a melhor forma que você e seu companheiro cego encontraram para fazer as atividades juntos?

8._Foi mais difícil ser o cego ou o acompanhante? Por quê? (PROJETO ESCOLA VIVA, 2005, p. 13-15, grifo nosso).

O excerto destacado constitui-se em uma estratégia que busca despertar no discente dito normal sentimentos de comoção como, pena, tolerância, respeito, compaixão e solidariedade pelas deficiências. Sentimentos estes que correspondem à lógica da diversidade. Esta, tratada muitas vezes como sinônimo de diferença, é expressa com recorrência nos materiais analisados, tornando-se, assim, importante de ser problematizada.

Ao se buscar pelo conceito de diferença e de diversidade é possível observar que eles compartilham de uma rede de significação semelhante que "permite-nos distinguir o outro do um, o outro do mesmo. Quer dizer que o diferente ou diverso é o contrário do idêntico.” (FERRE, 2011, p. 195). No entanto, observa-se 
que, nos discursos da inclusão torna-se importante fazer algumas distinções entre eles. A diversidade está associada a um referente estático, limita-se a reafirmar o que já existe (SILVA, 2014), pois conserva identidades e compreensões hegemônicas, ao possibilitar o reconhecimento de outras culturas através de uma política de tolerância. Esta, ao mesmo tempo em que admite a existência das diferenças, pressupõe a superioridade de uns sobre os outros, já que para tolerar alguém é preciso que se estabeleça uma relação de dualidade, onde um ocupa o papel de tolerante (da superioridade), que aceita a existência daquele que ocupa o papel de tolerado (da inferioridade). Pode-se dizer assim que "a tolerância debilita as diferenças discursivas e mascara as desigualdades: quanto mais fragmentado se apresenta o mundo, mais ressoa o discurso da tolerância e mais se toleram formas desumanas de vida.” (SKLIAR, 2003, p. 133).

Já a diferença está relacionada a multiplicidade. Pode ser entendida como um movimento múltiplo, que se dissemina; como tudo aquilo que escapa a classificações e que por isso "[...]recusa a se fundir com idêntico." (SILVA, 2014, p. 101). Ela não é, portanto,

[...] uma obviedade cultural nem uma marca de "pluralidade"; as diferenças se constroem histórica, social e politicamente; não podem caracterizar-se como totalidades fixas, essenciais e inalteráveis; as diferenças são sempre diferenças; não devem ser entendidas como um estado não desejável, impróprio, de algo que cedo ou tarde voltará a normalidade; as diferenças dentro de uma cultura devem ser definidas como diferenças políticas - e não simplesmente como diferenças formais, textuais ou linguísticas; as diferenças, ainda que vistas como totalidades ou colocadas em relação com outras diferenças, não são facilmente permeáveis nem perdem de vista suas próprias fronteiras; a existência de diferenças existe independentemente da autorização, da aceitação, do respeito ou da permissão outorgado da normalidade. (SKLIAR, 1999, p. 22-23)

O excerto destacado dos documentos marca, assim, as deficiências pelo viés da diversidade, com o objetivo de familiarizar os ditos normais aos deficientes. Conforme se pode observar, o fragmento apresenta uma técnica de simulação, onde os docentes são orientados, primeiramente, a propor que o aluno dito normal vivencie a experiência de ser deficiente. Em um segundo momento, os docentes são orientados a realizar uma discussão com os alunos normais, propondo um exercício de autorreflexão, onde os mesmos são indagados e, desta forma, estimulados a expressar o que sentiram no momento em que vivenciaram as deficiências, de modo a construir uma subjetividade discente inclusiva.

Neste primeiro momento, em que é proposto aos docentes a realização de uma atividade para que o aluno dito normal vivencie a experiência de ser deficiente, observa-se que todas as simulações sugeridas se dão a partir da deficiência como perda, uma vez que, ao serem convidados para ocupar o lugar do outro, os alunos normais são privados de um dos seus sentidos. Desta forma, ao mesmo tempo em que essa atividade apresenta os deficientes como sujeitos inferiores aos não-deficientes, ela também reduz a deficiência a esta experiência. Assim, por ilusão, é possível pensar que, por alguns momentos, o discente dito normal pode 
vivenciar de fato a cegueira a partir da suposta perda de um sentido. Ao colocar-se no lugar do outro, o discente dito normal é levado a representar, portanto, as deficiências a partir das experiências que possui de si mesmo, constituindo-se como parâmetro em relação ao qual elas são construídas e avaliadas.

Nesse sentido observa-se que a noção de diferença só aparece nessa técnica de simulação como ato ou processo de diferenciação. De acordo com Silva (2014, p. 81) "a diferenciação é o processo central pelo qual a identidade e a diferença são produzidas". Sendo assim, ao vivenciar a experiência de ser deficiente, o discente dito normal constrói para si um sistema de significação sobre o que é ser deficiente e o que não é, ou seja, a ele é permitido realizar uma série de operações de classificação que demarcam as fronteiras, indicando características que permitem definir a si mesmo e o outro. A deficiência não deixa de aparecer nessa técnica como um "complemento do mesmo, mas também como aquilo que gera e determina o próprio conteúdo central da mesmidade. Assim, por exemplo, o deficiente restitui ao eu mesmo seu não-serdeficiente e também o constitui em relação às suas amplas margens [...] de normalidade.” (SKLIAR, 2003, p. 120). Nesse processo, os normais, não só tem sua normalidade exaltada, reforçada, como também se familiarizam com as deficiências, construindo saberes sobre elas a partir de si mesmo, tornando-as mais conhecidas e, por isso, menos estranhas.

Nesse processo de diferenciação observa-se que ao se colocar no lugar do outro deficiente é possível que os discentes normais o produzam a partir de um diferencialismo igualitarista. Ou seja, ainda que os documentos expressem a importância de olhar para as possibilidades e potencialidades das deficiências, pode-se dizer que nas simulações propostas, os discentes normais são levados a considerar a deficiência expressa em cada técnica a partir dessa perspectiva que compreende a diferença como um

[...] mito do arquétipo cultural, sustentado na suposição de que cada cultura está fundada em um padrão que outorga sentido pleno e coerência à vida, às ações e os intercâmbios de cada um de seus indivíduos. Assim, todos os negros vivenciem sua negritude da mesma maneira, todas as mulheres vivem seu gênero do mesmo modo, todos os mulçumanos experimentam uma única forma cultural de ser mulçumanos, todos os deficientes vivem sua deficiência de forma idêntica etc. (SKLIAR, 2003, p. 135).

A cultura do outro é apresentada nessas técnicas de forma superficial, como se a deficiência determinasse o sujeito, de modo que todos que possuíssem a mesma deficiência passassem pelas mesmas experiências, dificuldades e limitações. Nessa atividade, não se questiona, portanto, "as relações de poder que estão implicadas na produção das diferenças e das identidades culturais.” (LUNARDI, 2004, p. 12). Tampouco, se constrói o deficiente como um sujeito em potencial. No entanto, ela permite e ajuda a construir "um respeito à diversidade, que nada mais é do que a aceitação de um certo pluralismo que se refere sempre a uma norma ideal[...]" (LUNARDI, 2004, p. 9). 
Após vivenciar a experiência de ser deficiente, o discente dito normal participa de uma discussão, em que o professor aparece como coordenador e mediador. Nessa discussão ele passa a ser alvo das tecnologias do $e u^{i v}$, a fim de construir uma subjetividade discente inclusiva. Conforme é possível observar no excerto destacado, a partir de uma série de perguntas, busca-se fazer o aluno dito normal expor os sentimentos que vivenciou ao colocar-se no lugar do outro. Tal exercício possibilita ao discente dito normal julgar suas atitudes e comportamentos para com o outro, a partir da avaliação que faz sobre como é ser deficiente. Não se trata, portanto, de uma autorreflexão de forma direta, pois ela implica primeiramente o discente dito normal ver-se, expressar-se e narrar-se como sujeito deficiente a partir dos seus sentimentos, isto é, a expor o modo como compreende o outro. Este é constituído, deste modo, por meio de uma representação colonial, de "[...]um aparato de produção de conhecimentos que parece pertencer originalmente só ao colonizador; trata-se de seu saber, de sua ciência, de sua verdade [...]” (SKLIAR, 2003, p. 106) sobre a deficiência.

Externalizados seus sentimentos e, desta forma, expressada a verdade sobre a deficiência, o discente dito normal é levado a fazer uma autorreflexão a partir da experiência de si, pensando na relação que estabelece com o outro. Observa-se assim que a discussão proposta neste segundo momento das técnicas de simulação faz parte de uma pedagogia da sensibilização que torna os discentes normais alvos do que Larrosa identifica como sendo uma educação moral. Nas palavras do autor,

[...]a educação moral tem a ver com elementos do domínio moral, com disposições ou atitudes, com normas e com valores, mas de uma forma muito particular. Não se trata de apresentar um conjunto de preceitos e normas de conduta que as crianças deveriam aprender e obedecer. Tampouco se trata de modelar disposições ou hábitos. Nem sequer de doutrinar em uma série de valores. Uma vez que se trata de práticas centradas na aquisição, nelas não se ensina explicitamente nada. Entretanto, se aprendem muitas coisas. (LARROSA, 1994, p. 45)

Entendemos desta forma que, ao ser proposto que os discentes normais reflitam sobre a experiência de ser deficiente, busca-se sensibilizá-los a um conjunto de regras e valores que compõe uma moralidade dos comportamentos que correspondem a lógica da diversidade. O objetivo dessa prática consiste na “criação de atitudes de aceitação e convívio com a diversidade” (MACHADO, 2015, p. 139), o que permite que o discente dito normal cultive sentimentos que lhe possibilitam hospedar, tolerar e acolher o outro.

Pode-se dizer, assim, que as técnicas de simulação contribuem para a naturalização da presença do outro, pois, a partir delas, permite-se que a deficiência seja vista como uma normalidade diferente, na medida que a diferença que ostenta não gera ao sujeito dito normal estranhamento. Além disso, tais atitudes de aceitação e acolhimento da diversidade produzidas pelas técnicas de simulação, se mostram essenciais para a construção do último conjunto de práticas que compõe a tríade identificada nos documentos e que visa agir sobre a conduta do discente dito normal. Trata-se do que se pode chamar de cultura da colaboração. 


\section{Colaborar para incluir: investir em ações de coparticipação nas propostas escolares}

A cultura da colaboração é uma temática muito explorada no campo das ciências econômicas. No entanto, diante a crescente demanda contemporânea por sujeitos que tenham a competência de atuar em tarefas cooperativas, tal temática atinge o campo da educação. Já é possível visualizar a cultura da colaboração sendo discutida como uma proposta importante de ser colocada em prática no contexto inclusivo em alguns documentos oficiais, como os que foram analisados nesta pesquisa. Nestes materiais, ela aparece como mais uma das formas de agir sobre a conduta do discente dito normal e de sensibilizá-lo a assumir uma postura acolhedora, tolerante e de respeito para com a diversidade, visando uma convivência produtiva entre o sujeito normal e anormal. São essas atitudes que permitem a instauração de uma cultura da colaboração, conforme vemos seguir:

É necessário então, aprofundar a análise dos fatores e das condições que possibilitam avançar em direção a práticas inclusivas, transformando a cultura escolar em uma cultura de colaboração e de valorização da diversidade, de respeito às crenças e às características do outro, bem como de ampliação das expectativas dos professore(a)s quanto ao potencial de aprendizagem dos aluno(a)s. A promoção de uma cultura de apoio e colaboração fundada em relações de respeito e cooperação entre aluno(a)s, professore(a)s, pais e apoio interno ou externo à escola (outros profissionais, organizações, etc.) constitui fator chave para o desenvolvimento e a aprendizagem da comunidade escolar em sua totalidade. (EDUCAR NA DIVERSIDADE, 2006, p. 115, grifo nosso).

Apesar de parecer contrária à lógica neoliberal, por enfatizar as práticas de cooperação, a cultura da colaboração articula-se com a governamentalidade neoliberal, pois convoca todos como responsáveis pela inclusão. Vejamos alguns exemplos desses discursos:

\section{2 - Estratégias de aprendizagem cooperativa}

Diversos estudos têm mostrado que a aprendizagem cooperativa provoca repercussões importantes não apenas nas relações interpessoais, mas também na aprendizagem de conteúdos ou resultado escolar. Por outro lado, tais estratégias permitem que os docentes possam dedicar mais tempo aos grupos com maior necessidade de apoio, além de serem particularmente úteis em classes muito numerosas. (EDUCAR NA DIVERSIDADE, 2006, p. 30, grifo nosso).

É fato comprovado à sociedade que as crianças não aprendem apenas com o professor(a), mas também com as outras crianças. [...] A utilização deste tipo de técnica pressupõe uma grande ajuda para o professor(a), por facilitar trabalho autônomo dos alunos(a)s, permitindo-lhe dedicar mais atenção àqueles que dela mais necessitam. (EDUCAR NA DIVERSIDADE, 2006, p. 176, grifo nosso).

Observa-se que a cultura da colaboração é apresentada a partir de aprendizagens cooperativas que marcam a descentralização do papel do professor. Desta forma, pode-se dizer que, esta cultura se entrelaça 
com um dos principais princípios neoliberais: o da autocondução ou autogoverno. O docente é apresentado como um mediador da aprendizagem dos seus alunos. Sua função passa a ser administrar os meios de promoção da independência, visando que eles se responsabilizem pela construção do seu processo de aprendizagem. Conforme aponta Lockmann (2010), a descentralização do papel do professor, pressupõe a centralização dos alunos nos processos educativos. Os alunos são vistos, assim, como sujeitos ativos que aprendem por sua própria experiência e que, por isso, são capazes de se autoconduzirem, assumindo o compromisso de investir nas suas aprendizagens.

Além disso, estes discursos mostram que a cultura da colaboração coloca em operação práticas cooperativas que agem sobre a conduta do discente dito normal, transformando-o em sujeito parceiro no processo de educar e administrar as diferenças. No momento em que o discente dito normal se coloca como protagonista do seu processo educativo, não só troca experiências e auxilia os colegas nas suas aprendizagens, como também exige menos intervenções do professor que passa a auxiliar aqueles que apresentam mais dificuldades na autocondução da sua educação. Nesse sentido, o discente dito normal é visto como aquele que contribui para a produção de uma inclusão produtiva do aluno que apresenta dificuldades de aprendizagem.

Pode-se dizer que, desta forma, a aprendizagem cooperativa proposta pela cultura da colaboração, para além de promover uma prática solidária, visa inserir os sujeitos escolares na lógica empresarial do neoliberalismo. Vejamos abaixo:

A maior parte dos professores(a)e(a)s reconhece que o desenvolvimento pessoal e social é um item importante do currículo. Queremos que nossos alunos(a)s se realizem vivendo melhor, trabalhando e distraindo-se em um contexto que lhes permita relacionar-se e desenvolver-se socialmente. Se a aprendizagem acontece sobretudo mediante a competitividade entre aluno(a)s ou de forma isolada, reduzem-se as possibilidades de serem alcançados os objetivos de integração social anteriormente mencionados. Ao contrário, nas aulas em que são estimulados e ajudados a trabalhar de forma cooperativa, os alunos(a)s têm ao mesmo tempo a oportunidade de progredir nestes aspectos de desenvolvimento pessoal e de alcançar seus propósitos escolares.

De um ponto de vista mais prático, a aprendizagem na base da cooperação pode fazer com que os aluno(a)s dependam menos de seus professor(a)e(a)s. Procura-se que os aluno(a)s trabalhem juntos, apoiando-se mutuamente e juntos buscando soluções para os problemas apresentados em diversas situações e atividades de aprendizagem. Quando se consegue colocá-la em prática - o que nem sempre é fácil... - esta maneira de trabalhar deixa tempo para que os professores(a)e(a)s se concentrem em outros aspectos importantes da vida na sala de aula. Ao contrário, muitas outras metodologias de trabalho em salas de aula reforçam a dependência $\operatorname{dos} \operatorname{alunos(a)s~em~relação~ao~professor(a),~}$ desperdiçando, assim, o recurso educacional mais valioso: o tempo do professor(a). A seguinte parábola talvez resuma esta questão: "A instituição escolar é a única empresa em que o patrão faz todo o trabalho enquanto os 
trabalhadores ficam sentados, olhando!". (EDUCAR NA DIVERSIDADE, 2006, p. 209, grifo nosso).

A escola é apresentada neste discurso como “[...]essa multiplicação da forma "empresa” no interior do corpo social[...]" (FOUCAULT, 2008a, p. 203), onde os sujeitos escolares precisam ser produzidos como sócios/parceiros empreendedores e empresários de si mesmos. No contexto do neoliberalismo, não só a escola representa uma sociedade formalizada pela lógica empresarial, como cada indivíduo que a compõe também “[...]deverá ser para si mesmo e para sua família, de certo modo, uma empresa." (FOUCAULT, 2008a, p. 283). O princípio de autocondução e autogoverno é, portanto, reforçado, uma vez que o sujeito escolar passa a ser visto como um trabalhador-empresa. Nessa lógica, a cultura da colaboração permite cada um tornar-se responsável por uma atribuição que contribui para o funcionamento de uma inclusão produtiva.

Com relação ao discente dito normal, observa-se que para manter esta inclusão funcionando, não basta apenas que ele gerencie a si mesmo, a sua aprendizagem e tolere o outro. É necessário também que ele seja um investidor em ações solidárias, isto é, que ele se preocupe em investir no outro, contribuindo para garantir a condição e a possibilidade de participação de todos na sociedade. Desta forma, o discente dito normal enquanto indivíduomicroempresa "[...] passa a colega/sócio/parceiro sensível [...] e atento às vantagens da convivência escolar." (MACHADO, 2015, p. 118).

Pode-se dizer, assim, que a cultura da colaboração se manifesta como o que Gadelha (2013) nomeia por cultura do empreendedorismo, encontrando-se associada à noção de capital-humano. Compreende-se que o empreendedorismo é colocado em operação pela governamentalidade neoliberal como um modo de vida em que o sujeito busca investir constantemente em si mesmo, de modo a ampliar seu capital-humano, ou seja, suas competências, habilidades e destrezas, preservando-as e conservando-as.

Dentre as várias formas de empreendimento que os sujeitos podem fazer sobre si para maximizar seu capital-humano, o investimento educacional destaca-se como o principal deles. No contexto da educação inclusiva, uma forma de fazer este investimento pode ser observada através do discurso destacado, que ressalta a convivência pela aprendizagem cooperativa como uma parceria produtiva a ser desenvolvida. Auxiliar o outro com a sua aprendizagem é visto como uma forma de "[...] aprender com o outro, ou melhor, empreender e gerir essa relação de parceria com o outro é investir em si mesmo, melhorando seus próprios níveis de concorrência.” (MACHADO, 2015, p. 152). Ou seja, ao agir como um investidor em ações solidárias, o sujeito discente dito normal não investe apenas no outro (sujeito dito anormal), mas também em si mesmo por meio das habilidades sociais que passa a desenvolver. Esta ideia é reforçada nos documentos oficiais analisados, conforme mostra os exemplos destacados abaixo: 
O aluno sem deficiência mental, por sua vez, não só vai continuar aprendendo aquilo que aprenderia, mas vai ter melhores ocasiões de apreender, ou seja, de reter aquilo que lhe foi ensinado, ainda mais se puder trabalhar em grupo e compartilhar o aprendizado ensinando os seus colegas de turma. (ACESSO A ESCOLA INCLUSIVA, 2004, p. 51, grifo nosso).

[...]para aprender de forma cooperativa, não é suficiente organizar as atividades em grupos, mas de forma que todos os envolvidos compartilhem um objetivo comum. Cada participante deve contribuir de acordo com suas possibilidades e capacidade para a realização da tarefa e alcance do objetivo. Neste sentido, toda colaboração é válida para a realização da atividade ou tarefa. Um aspecto fundamental relacionado com os grupos de aprendizagem cooperativa é que estes devem ser heterogêneos, de tal modo que cada grupo deve se constituir de representantes do conjunto da classe. [...] (EDUCAR NA DIVERSIDADE, 2006, p. 30, grifo nosso).

O trabalho coletivo e diversificado nas turmas é compatível com a vocação da escola de formar as novas gerações. É nos bancos escolares que aprendemos a viver entre os nossos pares, a dividir as responsabilidades e repartir as tarefas. [...] Os tutores têm sido uma solução muito bem-vinda a todos, despertando nos alunos o hábito de compartilhar o saber. $O$ apoio ao colega com dificuldade é uma atitude extremamente útil e humana que tem sido pouco desenvolvida nas escolas. (ACESSO A ESCOLA COMUM, 2004, p. 35, grifo nosso).

No primeiro excerto destacado observa-se que desenvolver uma sensibilidade inclusiva faz da ação solidária uma conduta econômica, bem como transforma a relação de convivência em uma relação de custo/benefício que será sempre positiva para o discente dito normal. Ao aprender com o outro, ele não só expande seu capital-humano, como também gerencia o risco que o sujeito dito anormal pode causar futuramente para ele mesmo, para a população e para o Estado.

Já os outros dois fragmentos mostram a relação de desigualdade que sustenta e possibilita o desenvolvimento das práticas cooperativas. Tal relação evidencia-se na ênfase dada pelos discursos sobre a importância da heterogeneidade das capacidades dos sujeitos para o desenvolvimento da aprendizagem cooperativa. Conforme se pode visualizar nos discursos, para que essa aprendizagem aconteça é preciso que um sujeito seja auxiliado, dirigido e/ou conduzido no seu processo de aprendizagem por outro mais experiente, com maiores conhecimentos. Pode-se dizer, assim, que a cultura da colaboração através das práticas cooperativas, ainda que seja apresentada pelo viés da solidariedade para com o outro, manifesta a existência de uma relação de desiquilíbrio entre as partes, se configurando como uma potente estratégia de gerenciamento da diferença por meio da dominação por tutela.

A dominação por tutela é compreendida como um movimento de condução que posiciona o dito anormal como sujeito incapaz de se autoconduzir, tornando-o objeto de ações tutelares para sua própria proteção. Nessas ações compreende-se que a tutela é determinada pela racionalidade daqueles que a colocam em operação. Desta forma, não há uma participação ativa por parte do tutelado, visto que as ações 
tutelares se pautam no princípio da sua neutralidade. Para que elas ocorram, não é necessário obter o consentimento do outro, pois nessa relação, não se espera nenhum sentimento e reação por parte daquele que é tutelado. Entende-se assim que diferente de outras formas de dominação "a tutela não dobra e nem quebra o outro, mas apenas o conduz, pois ele é visto como um indivíduo incompleto, incapaz de decidir por si mesmo e até mesmo, muitas vezes, de compreender minimamente o mundo." (VEIGA-NETO; LOPES, 2013, p. 111 - 112).

Se é possível pensar as práticas cooperativas desta forma, é porque a relação desigual entre as capacidades intelectuais das crianças necessária para o desenvolvimento dessas práticas, pressupõe a existência de um sujeito capaz de se autoconduzir e conduzir o outro, que não possui ou não consegue desenvolver sua autocondução da forma desejada ou esperada. Conforme aponta Veiga-Neto e Lopes (2013, p. 121) "a condição de menoridade colocada àquele que se mantém alienado ao outro é condição necessária para que a dominação por tutela aconteça." Nesse sentido, entende-se que nas práticas cooperativas os anormais são tutelados pelos normais e sua diferença passa a ser gerenciada, de modo que o dito normal passa a decidir e determinar as formas de aprendizagem do outro.

Diante disso, compreendemos que os discursos destacados reforçam a responsabilização dos sujeitos normais no gerenciamento das diferenças a medida que "[...] todos devem estar abertos para o outro, todos devem ter consciência de suas fragilidades, todos devem ser capazes, em alguma medida, de conduzir e orientar o outro. Em síntese, todos somos parceiros e corresponsáveis, juntamente com o Estado, pela inclusão [...]”" (VEIGA-NETO; LOPES, 2013, p. 120). Através da cultura da colaboração, entende-se, portanto, que os anormais são tutelados pelos normais, tendo suas diferenças apagadas em nome da solidariedade, da tolerância, do politicamente correto revestido por discursos que, muito mais do que reconhecer as diferenças, servem para transparecer e colocar em destaque o caráter arrogante da mesmidade.

\section{Considerações finais:}

Com este artigo buscou-se mostrar a ênfase das práticas de inclusão contemporâneas sobre os sujeitos ditos normais e como elas colocam em funcionamento estratégias de governamento, que convocam professores e discentes a sensibilizarem-se ao projeto inclusivo. Mais especificamente, a partir dos excertos analisados, foi possível observar a existência de uma tríade: reflexão-simulação-colaboração, agindo sobre a conduta do discente dito normal.

Ao analisar as práticas de reflexão presentes nos documentos compreende-se que elas fazem parte de um movimento de aceitação, tolerância e respeito a diversidade, contribuindo para o processo de naturalização das diferenças e para o alargamento da noção de normalidade. As técnicas de simulação 
analisadas reforçam ainda mais esses entendimentos, uma vez que elas têm por objetivo familiarizar o dito normal com as deficiências. Conforme foi possível observar, tais técnicas contribuem para reduzir a deficiência a limitação ao marcar as diferenças pela lógica da diversidade, dando possibilidades para que o dito normal se constitua como parâmetro para avaliar, conhecer e narrar o outro. Além disso, o último eixo tratou sobre a cultura da colaboração evidenciando a partir dos fragmentos destacados a orientação para o desenvolvimento de uma convivência produtiva, onde os discentes normais são mobilizados a investir em ações solidárias, de modo a gerenciar a si mesmo e ao outro. Assim, evidenciando a inclusão enquanto uma estratégia de governamento entrelaçada aos princípios neoliberais.

Importa ressaltar, que neste artigo, não se buscou fazer um juízo de valor sobre as atividades propostas nos documentos, mas desnaturalizar o caráter salvacionista e as ações solidárias que nos convidam a pensar na inclusão e na convivência com o outro a partir da comoção, da pena ou da benevolência; sentimento fraternos, mas perversos, pois colocam esse outro sempre no lugar da falta e da incapacidade. Assim, compreendemos que este artigo contribui para pensarmos nos efeitos que tais práticas produzem no modo como os sujeitos são narrados e compreendidos pelo olhar da normalidade e por que não, para pensarmos em outras práticas de inclusão? Em um encontro com o outro que desloque a ênfase da normalidade e da piedade, para que haja, nestas oportunidades, possibilidades para o reconhecimento da existência das diferenças.

\section{Referências}

BRASIL. Educar na diversidade: material de formação docente. 3. ed. Brasília: Ministério da Educação, Secretaria de Educação Especial, 2006.

BRASIL. Projeto Escola Viva: garantindo o acesso e a permanência de todos os alunos na escola: necessidades educacionais especiais dos alunos. 5 v Brasília: Ministério da Educação, Secretaria de Educação Especial, 2005.

BRASIL. O Acesso de Alunos com Deficiência às Escolas e Classes Comuns da Rede Regular. 2. ed. Brasília: Procuradoria Federal dos Direitos do Cidadão, 2004.

FERRE, Nuria Pérez de Lara. Identidade, diferença e diversidade: manter viva a pergunta. In: LARROSA, Jorge. SKILAR, Carlos (Org.). Habitantes de Babel: políticas e poéticas da diferença. Belo Horizonte: Autêntica, 2011. p.195-214.

FOUCAULT, Michel. A ordem do discurso: aula inaugural no Collège de France, pronunciada em 2 de dezembro de 1970. 23. ed. São Paulo: Edições Loyola, 2013.

FOUCAULT, Michel. Nascimento da biopolítica. São Paulo: Martins Fontes, 2008a.

FOUCAULT, Michel. Segurança, Território, População. São Paulo: Martins Fontes, 2008b. FOUCAULT, Michel. Do governo dos vivos: curso no Collège de France: 1979-1980: excertos. 2. ed. São Paulo: Centro de Cultura Social; Rio de Janeiro: Achiamé, 2011. 
GADELHA, Sylvio. Biopolítica, governamentalidade e educação: introdução e conexões a partir de Michel Foucault. Belo Horizonte: Autêntica Editora, 2013.

KLEIN, Delci Heinle. IDEB e maquinarias: A produção, a quantificação e a expressão da qualidade da educação brasileira. 2017. 171f. Tese (Doutorado em Educação). Programa de Pós-Graduação em Educação. Faculdade de Educação da Universidade Federal do Rio Grande do Sul, Porto Alegre, 2017.

LARROSA, Jorge. Tecnologias do eu e educação. In: Silva, Tomaz Tadeu. O sujeito da educação. Petrópolis: Vozes, 1994, p. 35-86.

LOCKMANN, Kamila. Inclusão Escolar: Saberes que operam para governar a população. 2010. $180 f$. Dissertação (Mestrado em Educação). Programa de Pós-Graduação em Educação. Faculdade de Educação da Universidade Federal do Rio Grande do Sul, Porto Alegre, 2010.

LOPES, Maura Corcini; FABRIS, Eli Henn. Inclusão \& Educação. Belo Horizonte: Autêntica, 2013.

LOPES, Maura Corcini et al. Inclusão e biopolítica. Cadernos IHU Ideias, Unisinos, a. 8, n. 144, 2010.

MACHADO, Fernanda Camargo. A racionalidade neoliberal nas práticas de sensibilização para a inclusão escolar de deficientes. 2015. 175f. Tese (Doutorado em Educação). Programa de Pós-Graduação em Educação. Universidade Federal de Santa Maria, Santa Maria, 2015.

RECH, Tatiana Luiza. A emergência da inclusão escolar no governo FHC: movimentos que a tornaram uma "verdade" que permanece. 2010. 186f. Dissertação (Mestrado em Educação). Programa de PósGraduação em Educação. Universidade do Vale do Rio dos Sinos (UNISINOS), São Leopoldo, 2010.

SILVA, Tomaz Tadeu. Identidade e Diferença: A perspectiva dos Estudos Culturais. Petrópolis, RJ: Vozes, 2014.

SKLIAR, Carlos. Pedagogia (improvável) da diferença: e se o outro não estivesse aí? Rio de janeiro: DP\&A, 2003.

SKLIAR, Carlos. A invenção e a exclusão da alteridade "deficiente" a partir dos significados da normalidade. Educação \& Realidade. n. 24 (1): p. 15-32. jul./dez. 1999.

SOMMER, Luís Henrique. A ordem do discurso escolar. Revista Brasileira de Educação vol. 12, n. 34, p. 57-67, jan./abr. 2007.

VEIGA-NETO, Alfredo; LOPES, Maura Corcini. Rebatimento: a inclusão como dominação do outro pelo mesmo. MUCHAIL, Salma Tannus, FONSECA, Márcio Alves da, VEIGA-NETO, Alfredo. (Org.). $O$ mesmo e o outro: 50 anos de história da loucura, 2013. p. 103-124.

VEIGA-NETO, Alfredo. Foucault \& a Educação. 2. ed. Belo Horizonte: Autêntica, 2005a.

VEIGA-NETO, Alfredo. Coisas do governo... In: RAGO, Margareth; ORLANDI, Luiz Benedicto Lacerda Orlandi \& VEIGA- NETO, Alfredo. (Org.). Imagens de Foucault e Deleuze: ressonâncias nietzschianas. Rio de Janeiro: DP\&A, 2005b. p. 13-34.

Recebido em: 30/04/2020.

Revisto em: 03/08/2020.

Aceito em: 11/08/2020. 
Notas

${ }^{\text {i }}$ Professora de Educação Infantil no município de Rio Grande/RS e no Colégio Marista São Francisco. Mestre em Educação pela Universidade Federal do Rio Grande - FURG. Graduada em Pedagogia Licenciatura pela Universidade Federal do Rio Grande FURG. Participa do Grupo de Estudos e Pesquisa em Educação e In/Exclusão (GEIX/FURG/CNPq), do Grupo de Estudos e Pesquisa em Inclusão (GEPI/UNISINOS/CNPq) e do Núcleo de Estudo e Pesquisa em Educação da Infância (NEPE/FURG/CNPq). E-mail: camilabttc@gmail.com Rio Grande do Sul. ORCID: https://orcid.org/0000-0003-1440-2812

ii Professora do Instituto de Educação e do Programa de Pós-Graduação em Educação da Universidade Federal do Rio Grande FURG. Doutora (2013) e Mestre (2010) em Educação pela Universidade Federal do Rio Grande do Sul - UFRGS. Coordena o Grupo de Estudos e Pesquisa em Educação e In/exclusão (GEIX/FURG/CNPq) e é pesquisadora integrante do Grupo de Estudo e Pesquisa em Inclusão (GEPI/UNISINOS/CNPq). Editora associada da Revista Brasileira de Educação Especial - RBEE. Bolsista Produtividade em Pesquisa do CNPq - Nível 2. E-mail: kamila.furg@gmail.com Rio Grande do Sul. ORCID: https://orcid.org/0000-0002-1993-8088

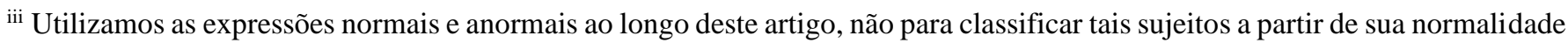
ou anormalidade, mas por entender que, independente da nomenclatura que se utiliza para referir esses sujeitos está-se marcando suas diferenças e posicionando-os como anormais no interior da norma. Mesmo aquelas terminologias consideradas politicamente corretas, também fazem essa operação de classificação, nada neutra nem inocente. Assim como Veiga-Neto (2001, p. 105), tomamos essa palavra emprestada de Foucault (2001), que a emprega "[...] para designar esses cada vez mais variados e numerosos grupos que a modernidade vem, incansável e incessantemente, inventando e multiplicando: os sindrômicos, deficientes, monstros e psicopatas (em todas as suas variadas tipologias), os surdos, os cegos, os aleijados, os rebeldes, os pouco inteligentes, os estranhos, os GLS iii, os “outros”, os miseráveis, o refugo enfim”.

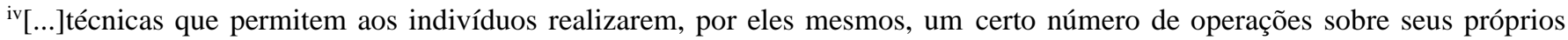
corpos, suas próprias almas, sobre seus próprios pensamentos, suas próprias condutas, e isso de maneira a transformarem a si mesmos, de modificarem a si mesmos e a atingirem um certo estado de perfeição, de felicidade, de pureza, de poder sobrenatural e assim por diante. (FOUCAULT, 2011, p. 155) 